\title{
The Fe oxidation and organic decomposition at Mesoproterozoic
}

\author{
XiaOmeI WANG ${ }^{1}$, DONALD E. CANFIELD ${ }^{2}$,SHUichang \\ ZHANG $^{1}$, HUAJIAN WANG ${ }^{1}$ \\ ${ }^{1}$ Research Institute of Petroleum Exploration and \\ Development, PO Box 910, Beijing, 100083, China \\ ${ }^{2}$ Institute of Biology and Nordic Center for Earth Evolution \\ (NordCEE), University of Southern Denmark, Campusvej \\ 55, 5230 Odense M, Denmark
}

We find a 1,400 million-year old (Ma) iron formation (IF) from the Xiamaling Formation of the North China Craton. we observed the IF in outcrop at three locations, and intercepted the IF in two cores. The IF-containing interval of the Xiamaling Formation comprises unit 5 of our informal classification scheme. Sedimentation in unit 5 is complex, ranging from laminated silty muds to thin event beds and crossbedded fabrics. The most $\mathrm{Fe}$-enriched layers are composed of densely packed siderite rhombs, with siderite also a dominant phase in X-ray diffraction (XRD). Tetramethyl aryl isoprenoid (TMAI) biomarkers linked to anoxygenic photosynthetic bacteria are identified. Molybdenum is not enriched. The carbonate associated with the siderite is highly depleted in ${ }^{13} \mathrm{C}$, with $\delta^{13} \mathrm{C}$ values ranging from approximately -8 to $-28 \%$. We observed a negative correlation pattern between TOC and HI, also between TOC and $\mathrm{Fe}$ in the high-Fe sediments.

The $\mathrm{Fe}$ enrichments themselves and high concentration of $\mathrm{V}$ speak to anoxic bottom water conditions ${ }^{1}$. The presence of TMAI is typically ascribed to the presence of an anoxygenic phototrophic population in an anoxic water-column setting. And low concentration of molybdenum might be expected in a low-sulfide environment ${ }^{2}$. The strong inverse correlation between $\mathrm{HI}$ and Fe content suggesting that the organic matter became more decomposed as Fe concentration increased.

So the Xiamaling IF displays an active iron cycle where iron oxides were deposited together with organic matter and where virtually the iron oxides were subsequently reduced during microbial dissimilatory iron reduction. This process of iron reduction appears to have been of similar efficiency to oxic respiration, degrading the organic matter to a poor state of preservation, These results point to substantial organic matter mineralization under the ferruginous conditions at Xiamaling Formation.

1. Emerson SR, Huested SS (1991) Ocean anoxia and the concentrations of molybdenum

and vanadium in seawater. Mar Chem 34:177-196

2. Algeo TJ, Rowe H (2012) Paleoceanographic applications of trace-metal concentration data. Chem Geol 324:6-18 